\title{
Analisis Disiplin Kerja Guru Ditinjau dari Supervisi Kepala Sekolah, Kompensasi dan Budaya Organsasi
}

\author{
Marlis Fatma ${ }^{1}$, Anoesyirwan Moeins ${ }^{2}$, Lusiana ${ }^{1}$ \\ ${ }^{1}$ Universitas Putra Indonesia YPTK Padang, Indonesia \\ ${ }^{2}$ Universitas Persada Indonesia, Jakarta \\ Email:marlis.fatma1@gmail.com
}

\begin{abstract}
This study aims to determine and analyze the Effect of Headmaster's supervision, Compensation and Organizational Culture on the Work Discipline of SMAN 1 Rao teachers, Pasaman Regency, both simultaneously and partially. The sample in this study were all SMAN 1 Rao teachers, totaling 63 people. The data analysis technique used was multiple linear regression, with the help of SPSS version 21.

The analysis proves that the headmaster's supervision and compensation partially significantly affects the work discipline of SMAN 1 Rao teachers, then Ha is accepted and Ho is rejected. While organizational culture did not affect and not significant the work discipline of SMAN 1 Rao teachers, Ho was accepted and Ha was rejected. Simultaneously the headmaster's supervision, compensation and organizational culture affected the work discipline of SMAN 1 Rao teachers. Among the three independent variables, the dominant variable is compensation. The contribution of determination (R2) of the three variables to the teacher's work discipline was $28,1 \%$ while the remaining $71.9 \%$ was contributed by other variables not included in this variable.

It is recommended to the headmaster of SMAN 1 Rao to maintain compensation, increase supervision and pay attention to the organizational culture so that it has improvement.
\end{abstract}

Keywords: supervision, commitment, organizational culture, discipline

\section{Pendahuluan}

Globalisasi telah menuntut banyak perubahan serta peningkatan diberbagai bidang kehidupan. Untuk itu perlu adanya sumber daya manusia yang berkualitas yang memiliki berbagai kompetensi, skill dan pengetahuan yang maksimal. Hal ini harus disiapkan sejak dini, salah satunya melalui pendidikan di sekolah. Pendidikan di sekolah tidak lepas dari peranan Guru dan Kepala Sekolah yang merupakan tolok ukur pengembangan sumber daya manusia. Menurut Hasibuan (2016), guru merupakan sumber daya yang penting bagi sekolah, karena memiliki bakat, tenaga dan kreativitas yang sangat dibutuhkan oleh sekolah untuk mencapai tujuannya.

Dalam mengimplementasikannya perlu didukung oleh sikap disiplin kerja guru. Disiplin menurut Sutrisno (2016) adalah sikap kesediaan seseorang untuk mematuhi dan menaati segala norma peraturan yang berlaku di organisasi. Disiplin kerja guru yang baik akan dapat mewujudkan visi dan misi sekolah, sedangkan disiplin yang menurun akan menjadi penghalang dan memperlambat pencapaian tujuan sekolah.

Di dalam disiplin kerja diperlukan sikap kesadaran dan kesediaan guru untuk melakukan pekerjaan dengan baik. Guru yang tidak disiplin akan membawa dampak negatif terhadap sekolah seperti turunnya mutu pendidikan. Dalam hal ini, peran Kepala Sekolah sebagai pemimpin sangat penting, kepala sekolah harus bisa menegur dan memberikan sangsi yang tegas terhadap guru yang tidak disiplin, baik dalam bentuk lisan maupun tulisan.

Salah satu penjabaran indikator ketidakdisiplinan guru dapat dilihat dari kepatuhan guru dalam melaksanakan tugas sekolah, seperti membuat perangkat pembelajaran yang terdiri dari 1). Analisis KI, KD dan SKL. 2). Silabus lengkap. 3). RPP lengkap. 4). Kriteria Ketuntasan Maksimal (KKM). 5). Program tahunan. 6). Program semester. 7). Absensi kehadiran siswa. 8). Jurnal kegiatan pembelajaran. 9). Jurnal penilaian sikap dan 10). Laporan penilaian. 
Dari 10 jenis perangkat pembelajaran, jurnal kegiatan pembelajaran dan jurnal penilaian sikap berada pada angka di bawah 50\%. Disinyalir hal ini terjadi karena adanya budaya malas dalam bekerja dan sikap kepala sekolah yang tidak memberikan sangsi yang tegas terhadap guru yang tidak mematuhi aturan. Selain itu kompensasi yang dianggap kurang memadai sehingga banyak guru yang enggan membuat tugas tersebut. Sebagai akibat ketidakdispilinan guru dalam menyelesaikan perangkat pembelajaran tepat waktu dengan hasil yang baik maka berdampak terhadap menurunnya mutu pendidikan yang dapat dilihat dari peringkat nilai UN dan nilai Dokumen 1 KTSP SMAN 1 Rao kabupaten Pasaman yang mengalami naik turun dalam tiga tahun terakhir ini.

Oleh karena itu perlu dilakukan perbaikan manajemen pendidikan dengan melakukan kegiatan supervisi oleh kepala sekolah pada guru, supaya dapat mengevaluasi dan meningkatkan disiplin kerja mereka. Supervisi menurut Sutrisno (2014:118) supervisi adalah pemberian pengarahan, membimbing kerja para karyawan, agar dapat melaksanakan kerja dengan baik tanpa membuat kesalahan.

Hasil supervisi yang dilakukan kepala sekolah menunjukkan bahwa nilai supervisi guru yang rendah ada 11 orang yaitu dengan nilai C (16\%). Guru yang memperoleh nilai supervisi A hanya 9 orang (13 $\%)$. Selebihnya nilai supervisi guru adalah adalah B yaitu 45 orang (70 \%). Hal ini menandakan bahwa guru belum maksimal dalam melaksanakan tugas-tugas sekolah.

Kegiatan supervisi tersebut diharapkan bermanfaat untuk meningkatkan disiplin kerja guru. Kepala sekolah dituntut untuk menumbuhkan motivasi guru dengan memberikan penghargaan kepada guru yang berprestasi dan hukuman kepada guru yang melanggar aturan. Tumbuhnya motivasi diharapkan dapat lebih memperkuat sikap disiplin guru dalam melaksanakan tugasnya.

Pemberian motivasi dengan harapan guru akan menggunakan kemampuannya dalam bentuk keahlian, keterampilan, tenaga dan waktunya untuk menyelenggarakan berbagai kegiatan yang menjadi tanggung-jawabnya dan menunaikan kewajiban dalam mencapai tujuan yang ditentukan.

Hal ini perlu di dukung dengan pemberian kompensasi yang seimbang dengan hasil yang telah diberikan kepada guru. Untuk itu hendaknya program kompensasi ditetapkan berdasarkan prinsip adil dan wajar, sesuai dengan undang-undang perburuhan, atau sesuai dengan peraturan kerja lembaga masing-masing. Dengan adanya kompensasi yang diberikan sesuai dengan haknya akan sangat mempengaruhi disiplin kerja seseorang.

Oleh karena itu, SMAN 1 Rao dan pemerintah telah memberikan beberapa jenis kompensasi terhadap guru. Dana yang diberikan sesuai dengan jenis kegiatan dan jumlah guru yang menerimanya. Dengan pemberian kompensasi yang sesuai, diharapkan dapat meningkatkan disiplin kerja para pegawai.

Untuk menjamin semua tugas dapat terlaksana dengan baik diperlukan kesadaran dan kemampuan yang maksimal dari setiap individu. Tanpa kedisiplinan, tujuan yang hendak dicapai akan sulit terealisasi serta akan timbul banyak hal yang menghalangi tercapainya tujuan organisasi.

Disamping itu, kepala sekolah juga dituntut untuk dapat menunjukkan prestasi kerja yang tinggi. Upaya-upaya untuk meningkatkan prestasi kerja, dapat dilakukan dengan melakukan pembenahan kepemimpinan sekolah sebagai unsur utama dalam manajemen peningkatan mutu pendidikan berbasis sekolah, sehingga sekolah dapat mandiri, kreatif, inovatif dalam melaksanakan kegiatan pendidikan sesuai dengan sumber daya pendidikan yang ada. Dalam proses pelaksanaan kegiatan diperlukan disiplin kerja agar dalam pelaksanaan kegiatan dapat berjalan tepat waktu, efektif, dan efisien.

Namun ada faktor lain yang mempengaruhi disiplin kerja seorang yaitu budaya organisasi. Budaya organisasi menurut Sedarmayanti (2017:50) budaya organisasi adalah seperangkat nilai yang mengendalikan interaksi antara satu individu dalam organisasi dengan individu dalam organisasi, atau organisasi lain sebagai pemasok dan anggota masyarakat yang dilayani. Budaya organisasi berkaitan erat dengan pemberdayaan pelaku organisasi dalam menjalankan roda usaha organisasi. Semakin kuat budaya organisasi, semakin besar dorongan untuk mencapai suatu keberhasilannya. Dengan adanya budaya organisasi nilai-nilai dapat dimengerti, ditanamkan dan dilakukan oleh pelaku organisasi. Budaya organisasi dapat memberikan manfaat yang baik bagi jalannya suatu organisasi agar dapat terus berjalan dengan produktif dan memberikan perkembangan yang positif dari hari ke hari. 
Berdasarkan hasil penelitian terdahulu yang dilakukan oleh Da'I Wibowo, 2009 menunjukkan bahwa supervisi kepala sekolah berpengaruh terhadap disiplin kerja guru. Sedangkan hasil penelitian Mahirah, (2018) menunjukkan bahwa tidak ada pengaruh supervisi kepala sekolah terhadap disiplin kerja guru.

Pada penelitian Anirul Awal (2019) dengan judul The Effect of Supervision on Increasing the Disciplinary of Employees Work In the Large Center Of Kerinci Seblat National Park Kota Sungai Penuh, mengatakan bahwa supervise berpengaruh terhadap disiplin kerja.

Begitu juga dengan hasil penelitian Badaruddin dan Mardiah Safitri (2018) bahwa terdapat pengaruh kompensasi terhadap disiplin guru. Hal ini juga didukung oleh penelitian Mailani Rabiulkhri dkk (2019) dengan judul The Effect Of Compensation And Organizational Commitment To Work Discipline With Job Satisfaction As Intervening Variables In Sakinah Wedding Organizer, bahwa kompensasi berpengaruh terhadap disiplin kerja.

Namun berbeda dengan budaya orgnisasi menurut Ujang Jaya (2015 tidak ada pengaruhnya terhadap disiplin kerja. Penelitian ini didukung oleh Ivonne Setiawati (2019) dengan judul penelitian The Effects of Organizational Culture, Leadership Style, Motivation, and Organizational Commitment on Employee Work Discipline at Pancaran Maitri Foundation, bahwa tidak ada pengaruh budaya organisasi dengan disiplin kerja.

Hasil penelitian ini tidak sama dengan Badaruddin dan Mardiah Safitri (2018) yang mengatakan bahwa terdapat pengaruh budaya organisasi terhadap disiplin guru.

Berdasarkan gambaran latar belakang masalah tersebut dan hasil penelitian terdahulu, maka perlu kiranya dilakukan penelitian untuk membuktikan pengaruh supervisi kepala sekolah, kompensasi dan budaya organisasi terhadap disiplin kerja guru di SMAN 1 Rao Kabupaten Pasaman. Oleh karena itu penulis tertarik untuk melakukan penelitian dengan judul “ Pengaruh Supervisi Kepala Sekolah, Kompensasi, dan Budaya Organisasi Terhadap Disiplin Kerja Guru di SMAN 1 Rao Kabupaten Pasaman ".

\section{Tinjauan Pustaka}

Disiplin kerja adalah kesadaran dan kesediaan seseorang untuk menaati semua peraturan perusahaan dan norma-norma sosial yang berlaku.

Indikator disiplin kerja menurut Afandi, (2016) yaitu: 1). Masuk kerja tepat waktu. 2). Penggunaan waktu secara efektif. 3). Tidak pernah mangkir/tidak bekerja. 4). Mematuhi semua peraturan organisasi atau perusahaan. 5). Target pekerjaan. 6). Membuat laporan kerja harian.

Supervisi kepala sekolah adalah usaha kepala sekolah untuk menstimulasi dan membimbing guru-guru agar lebih efektif dalam mengajar yang berupa perbaikan dalam hal belajar dan mengajar.

Indikator supervisi kepala sekolah menurut Purwanto, (2005) adalah: 1). Kunjungan kelas. 2). Pemberian semangat kerja guru. 3). Rapat-rapat pembinaan. 4). Pemahaman tentang kurikulum. 5).Pengembangan metode pengajaran. 6). Pengembangan bahan ajar. 7). Potensi pembelajaran. 8). Evaluasi pendidikan.

Kompensasi adalah pemberian penghargaan atau imbalan dalam bentuk langsung dan tidak langsung pada seseorang yang telah bekerja dengan baik.

Indikator kompensasi menurut Sutrisno (2016) adalah sebagai berikut: 1). Gaji. 2). Insentif. 3). Tunjangan. 4). Fasilitas

Budaya organisasi adalah suatu kebiasaan yang telah berlangsung lama dan dipakai serta diterapkan dalam aktivitas kerja sebagai salah satu pendorong untuk meningkatkan kualitas kerja para karyawan dan manajer perusahaan.

Indikator budaya organisasi menurut Robbins (2016) yaitu: 1). Inisiatif individual. 2). Toleransi. 3). Pengarahan. 4). Integrasi. 5). Dukungan manajemen. 6). Kontrol. 7). Sistem imbalan. 8). Pola komunikasi. 


\section{Metodologi Penelitian}

\section{Objek Penelitian.}

Dalam penelitian ini yang menjadi objek penelitin adalah guru SMAN 1 Rao, kabupaten Pasaman, Provinsi Sumatera Barat.

\section{Populasi dan sampel}

Sugiyono (2017) menyatakan bahwa populasi adalah wilayah generalisasi yang terdiri atas obyek atau subyek yang mempunyai kualitas dan karakteristik tertentu yang ditetapkan oleh peneliti untuk dipelajari dan kemudian ditarik kesimpulanya. Populasi dari penelitian ini adalah seluruh guru di SMAN 1 Rao Pasaman yang berjumlah 63 orang guru.

Sedangkan sampel menurut Sugiono (2017), adalah bagian dari jumlah dan karakteristik yang dimiliki oleh populasi tersebut. Teknik dalam pengambilan sampel ini menggunakan teknik total sampling (sampel keseluruhan), total sampling adalah teknik pengambilan sampel dimana jumlah sampel sama dengan populasi (Sugiyono, 2017). Alasan mengambil total sampling karena jumlah populasi yang kurang dari 100 sehingga seluruh populasi dijadikan sampel penelitian yaitu 63 orang.

\section{Jenis Teknik Pengumpulan Data}

Jenis data pada penelitian ini adalah berupa data kuantitatif yaitu data dari hasil angket atau kuesioner yang diberikan kepada sampel penelitian. Sumber data dalam penelitian ini yaitu sumber data primer dan skunder.

Data primer yakni data yang langsung diperoleh dari sampel penelitian. Data dari sampel penelitian yakni data supervisi kepala sekolah, kompensasi, budaya organisasi, dan disiplin kerja. Sedangkan data skunder adalah data yang diperoleh dari pihak lain seperti literatur dan penelitian terdahulu.

\section{Teknik Analisis Data}

Teknik analisis data yang digunakan adalah analisis statistik infrensial yang terdiri dari analisa deskriptif, uji validitas, uji reabilitas, uji asumsi klasik, analisis regresi berganda, uji statistik $t$, uji statistik $F$ dan koefisien determinasi.

\section{Hasil dan Pembahasan}

Hasil uji validitas menyatakan semua pernyataan pada variabel penelitian adalah valid. Hasil uji reabiltas menyatakan bahwa semua variabel adalah reliabel atau handal.

\section{Hasil Uji Asumsi Klasik Hasil Uji Normalitas}

Uji normalitas adalah pengujian tentang kenormalan distribusi data. Penggunaan uji normalitas karena pada analisis statistic parametik, asumsi yang harus dimiliki oleh data adalah bahwa data tersebut harus terdistribusi secara normal. Maksud data terdistribusi secara normal adalah bahwa data akan mengikuti bentuk distribusi normal, maka hasilnya dapat dilihat pada tabel di bawah ini:

\begin{tabular}{|} 
Tabel1. Hasil Uji Normalitas \\
\begin{tabular}{|c|c|c|c|c|}
\hline & $\begin{array}{c}\text { kompen } \\
\text { isi }\end{array}$ & $\begin{array}{c}\text { badaya } \\
\text { sasi } \\
\text { organis } \\
\text { asi }\end{array}$ & $\begin{array}{c}\text { disipl } \\
\text { in }\end{array}$ \\
\hline $\begin{array}{c}\text { Asymp. } \\
\text { Sig. (2- } \\
\text { tailed) }\end{array}$ & 0,707 & 0,259 & 0,507 & 0,07 \\
& & & 6 \\
\hline
\end{tabular}
\end{tabular}

Sumber: SPSS 21 dan data primer diolah

Dari tabel di atas diketahui bahwa data terdistribusi normal sehingga layak dipakai untuk analisis regresi berganda. 


\section{Hasil Uji Multikolinieritas}

Uji multikolinieritas ini bertujuan untuk menguji apakah model regresi ditemukan adanya korelasi antar variabel bebas (independen). Model regresi yang baik, seharusnya tidak terjadi korelasi diantara variabel independen. Jika variabel independen saling berkorelasi, maka variabel-variabel ini tidak orthogonal. Untuk mendeteksi adanya multikolinieritas, dapat dilihat value inflation faktor (VIF). Apabila nilai VIF $>10$, terjadi multikolinieritas. Sebaliknya, jika $\mathrm{VIF}<10$, tidak terjadi multikolinieritas. Maka hasilnya dapat dilihat dari tabel di bawah ini:

Tabel 2. Hasil Uji Multikolinieritas

\begin{tabular}{|l|c|c|}
\hline Variabel bebas & Tolerance & VIF \\
\hline X1=supervisi & 0,600 & 1,665 \\
\hline X2=kompensasi & 0,639 & 1,565 \\
\hline $\begin{array}{l}\text { X3=budaya } \\
\text { organisasi }\end{array}$ & 0,913 & 1,095 \\
\hline
\end{tabular}

Sumber: SPSS 21 dan data primer diolah

Dari tabel di atas dapat diketahui bahwa semua nilai tolerance $>0,10$ dan hasil perhitungan nilai VIF < 10 ini berarti tidak terjadi gejala multikolinieritas antar variabel independen. Dengan demikian dapat disimpulkan bahwa persamaan regresi yang digunakan sebagai prediksi dalam penelitian ini bebas dari asumsi klasik.

\section{Hasil Uji Heteroskedastisitas}

Pengujian ini digunakan untuk melihat apakah variabel pengganggu mempunyai varian yang sama atau tidak. Heteroskedastisitas mempunyai suatu keadaan bahwa varian dari residual suatu pengamatan yang lain berbeda. Salah satu metode yang digunakan untuk menguji ada tidaknya heteroskedastisitas akan mengakibatkan penaksiran koefisien-koefisien regresi menjadi tidak efisien. Hasil penaksiran akan menjadi kurang dari semestinya. Dasar analisisnya adalah sebagai berikut:

Tabel 3. Hasil Uji Heteroskedastisitas

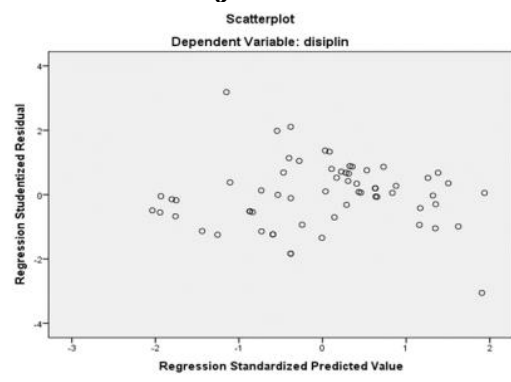

Sumber: SPSS 21 dan data primer diolah

Dari data di atas dapat diketahui bahwa tidak terjadi heteroskedastisitas karena, titik titik data menyebar di bawah dan di atas atau sekitar angka 0 dan titik titik data tidak menyebar membentuk pola.

\section{Hasil Analisis Regresi Berganda}

Analisis ini digunakan untuk mengetahui pengaruh Supervisi Kepala sekolah $\left(\mathrm{X}_{1}\right)$, Kompensasi $\left(\mathrm{X}_{2}\right)$ dan Budaya Organisasi $\left(\mathrm{X}_{3}\right)$ terhadap Disiplin Kerja Guru $(\mathrm{Y})$. Adapun bentuk regresinya adalah: 
Tabel 4. Hasil Analisis Regresi Berganda

Coefficients

\begin{tabular}{|l|l|r|l|l|l|}
\hline \multirow{2}{*}{ Model } & \multicolumn{2}{|l|}{$\begin{array}{l}\text { Unstandardized } \\
\text { Coefficients }\end{array}$} & $\begin{array}{l}\text { Standardized } \\
\text { coefficients }\end{array}$ & \multirow{2}{*}{ Sig } \\
\cline { 2 - 5 } & B & $\begin{array}{l}\text { Std. } \\
\text { Error }\end{array}$ & Beta & & \\
\hline (constant) & 4,743 & 11,795 & & 0,402 & 0,689 \\
Supervisi & 0,372 & 0,155 & 0,334 & 2,406 & 0,019 \\
Kompensasi & 0,411 & 0,198 & 0,280 & 2,079 & 0,042 \\
Budaya organisasi & 0,092 & 0,151 & 0,069 & 0,610 & 0,544 \\
\hline
\end{tabular}

Sumber: data primer yang diolah

Berdasarkan data di atas maka dapat diketahui persamaan regresinya yaitu :

$\mathrm{Y}=4,743+0,372 \mathrm{X}_{1}+0,411 \mathrm{X}_{2}+0,092 \mathrm{X}_{3}$

Di mana:

$\mathrm{Y}=$ disiplin kerja

$\mathrm{X}_{1}=$ supervisi

$\mathrm{X}_{2}=$ kompensasi

$\mathrm{X}_{3}=$ budaya organisasi

Persamaan regresi tersebut berarti:

1.Konstanta sebesar 4,743 artinya apabila supervisi kepala sekolah, kompensasi dan budaya organisasi tidak ada maka disiplin kerja guru tetap sebesar konstanta 4,743.

2.Koefisien regresi positif sebesar 0,372 artinya apabila supervisi kepala sekolah ditingkatkan sebesar satu satuan, dengan asumsi kompensasi dan budaya organisasi diabaikan, maka akan mengakibatkan peningkatan disiplin kerja guru sebesar 0,372 .

3.Koefisien regresi positif sebesar 0,411 artinya apabila kompensasi ditingkatkan sebesar satu satuan, dengan asumsi supervisi kepala sekolah dan budaya organisasi diabaikan, maka akan mengakibatkan peningkatan disiplin kerja guru sebesar 0,411 .

4.Koefisien regresi positif sebesar 0,092 artinya apabila budaya organisasi ditingkatkan sebesar satu satuan, dengan asumsi supervisi kepala sekolah dan budaya organisasi diabaikan, maka akan mengakibatkan peningkatan disiplin kerja guru sebesar 0,092.

Tabel 5. Hasil Uji t (parsial)

\begin{tabular}{|l|c|c|c|}
\hline $\begin{array}{l}\text { Faktor } \\
\text { Independent }\end{array}$ & $\begin{array}{c}\text { t- } \\
\text { hit } \\
\text { un } \\
\mathbf{g}\end{array}$ & $\begin{array}{l}\text { t- } \\
\text { tab } \\
\text { el }\end{array}$ & sig \\
\hline Supervisi (X1) & $\begin{array}{c}2,40 \\
6\end{array}$ & 2,00 & 0,01 \\
& 6 & 9 \\
\hline $\begin{array}{l}\text { Kompensasi } \\
(X 2)\end{array}$ & 2,07 & 2,00 & 0,04 \\
\hline Budaya & 0,61 & 0 & 2 \\
organisasi (X3) & 0 & 0 & 0,54 \\
\hline
\end{tabular}

Sumber: Data Primer Diolah, 2020

Uji t dimaksud untuk menguji signifikan pengaruh variabel bebas dan terikat secara parsial. Dimana pengujian ini membandingkan antara probabilitas signifikan dengan alpha 0,05. Dari hasil pengujian ini bila probabilitas signifikan lebih kecil dari pada alpha 0,05 maka diperoleh Ho ditolak dan Ha diterima, berarti ada pengaruh X terhadap Y

Probabilitas signifikan lebih besar daripada alpha 0,05 maka Ho diterima dan Ha ditolak, berarti tidak ada hubungan. Derajat kebebasan (df) n-k-1 yaitu $63-3-1=59$ ( $\mathrm{n}$ adalah jumlah responden dan $\mathrm{k}$ adalah jumlah variabel independent) sehingga hasil yang diperoleh untuk t-tabel sebesar 2,000. 


\section{Hasil Uji Secara Simultan (Uji F)}

Uji koefisien regresi secara bersama-sama dilakukan dengan Uji F (ANOVA). Uji ini digunakan untuk mengetahui apakah variabel independent secara bersama-sama berpengaruh signifikan terhadap variabel dependent. Atau untuk mengetahui apakah model regresi dapat digunakan untuk memprediksi variabel dependent atau tidak. Signifikan berarti hubungan yang terjadi dapat berlaku untuk populasi (dapat digeneralisasikan). Pengujian dilakukan dengan uji $\mathrm{F}$ (ANOVA). Uji $\mathrm{F}$ menggunakan taraf signifikan 0,05 (uji 2 sisi) dengan derajat kebebasan 95\%, alpha $=5 \%$, df 1 (jumlah variabel-1) atau 4 $-1=3$, dan df 2 (n-k-1) atau 59, maka hasil yang diperoleh untuk $\mathrm{F}_{\text {tabel }}$ sebesar 2,000.

Uji F dimaksud untuk menguji hipotesis dari penelitian yang menyatakan variabel supervisi kepala sekolah $\left(\mathrm{X}_{1}\right)$, kompensasi $\left(\mathrm{X}_{2}\right)$ dan budaya organisasi $\left(\mathrm{X}_{3}\right)$ mempunyai pengaruh signifikan terhadap disiplin kerja guru (Y). Hasil pengujian hipotesis secara bersama-sama dapat dilihat pada tabel 4.20 sebagai berikut:

Tabel 6. Anova

\begin{tabular}{|c|c|c|c|c|c|}
\hline Model & $\begin{array}{c}\text { Sum of } \\
\text { Square } \\
\text { s }\end{array}$ & $\mathrm{df}$ & $\begin{array}{c}\text { Mea } \\
\text { n } \\
\text { Squa } \\
\text { re }\end{array}$ & $\mathrm{F}$ & Sig \\
\hline Regres & 465,895 & 3 & 155 & 9,09 & 0,00 \\
\hline sion & 1007,85 & 5 & 298 & 1 & $0^{\mathrm{b}}$ \\
\hline Residu & 1 & 9 & 17,0 & & \\
\hline & 1473,74 & 6 & 82 & & \\
\hline Total & 6 & 2 & & & \\
\hline
\end{tabular}

a. Dependent variabel: disiplin

b. Predictors:(constant), budaya organisasi, kompensasi, supervise

Dari tabel di atas dapat dilihat pengujian ini dilakukan dengan cara membandingkan nilai $\mathrm{F}_{\text {hitung }}$ dengan $F_{\text {tabel }} k$ arena nilai $F_{\text {hitung }}$ lebih besar dari nilai $F_{\text {tabel }}(9,091>2,000)$ dengan tingkat signifikan $0,000<$ 0,05. Maka diperoleh Ho ditolak dan Ha diterima, yang berarti hal ini dilakukan secara bersama-sama antara supervisi kepala sekolah, kompensasi dan budaya organisasi berpengaruh terhadap disiplin kerja guru.

\section{Hasil Koefisien Determinasi $\left(\mathbf{R}_{2}\right)$}

Analisis Determinasi dalam regresi linear berganda digunakan untuk mengetahui persentase sumbangan pengaruh variabel independen terdiri dari supervisi kepala sekolah $\left(\mathrm{X}_{1}\right)$, kompensasi $\left(\mathrm{X}_{2}\right)$ dan budaya organisasi $\left(\mathrm{X}_{3}\right)$ terhadap disiplin kerja guru $(\mathrm{Y})$.

Tabel 7. Model Summary

\begin{tabular}{|c|l|l|l|c|}
\hline Model & $\mathrm{R}$ & $\begin{array}{l}\mathrm{R} \\
\text { Square }\end{array}$ & $\begin{array}{l}\text { Adjusted } \\
\mathrm{R} \\
\text { Square }\end{array}$ & $\begin{array}{l}\text { Std. Error } \\
\text { of the } \\
\text { Estimate }\end{array}$ \\
\hline 1 & $0,562^{\mathrm{a}}$ & 0.316 & 0,281 & 4.13307 \\
\hline
\end{tabular}

a. Predictors: (Constant), budaya oragnisasi, kompensasi, supervisi

Berdasarkan tabel di atas diperoleh angka Adjusted R Square sebesar 0,281 hal ini menunjukan bahwa sumbangan variabel supervisi kepala sekolah, kompensasi dan budaya organisasi sebesar $28,1 \%$ sedangkan sisanya yaitu 71,9\% dipengaruhi variabel lain yang tidak diteliti.

\section{Pembahasan Hasil Penelitian}

Disiplin kerja guru sangat penting supaya tujuan SMAN 1 Rao untuk meningkatkan kualitas pendidikan dapat tercapai.

Dari hasil penelitian tersebut dapat dijelaskan hal-hal sebagai berikut : 


\section{Pengaruh Supervisi Kepala Sekolah Terhadap Disiplin Kerja Guru}

Berdasarkan hasil pengujian hipotesis (H1) telah membuktikan variabel supervisi kepala sekolah berpengaruh terhadap disiplin kerja guru di SMAN 1 Rao, kabupaten Pasaman. Berdasarkan tabel 4.19 diperoleh nilai $t$ hitung $>\mathrm{t}$ tabel $(2,406>2,000)$ dengan tingkat signifikan $0,019<0,05$. Dapat diartikan bahwa variabel supervisi secara parsial berpengaruh positif dan signifikan terhadap displin kerja guru SMAN 1 Rao, kabupaten Pasaman. Oleh karena itu H1 diterima. Hal ini menunjukkan bahwa semakin tinggi tingkat supervisi maka semakin tinggi tingkat disiplin kerja guru, dan begitu juga sebaliknya, semakin rendah tingkat supervisi maka semakin rendah pula disiplin kerja guru di SMAN 1 Rao.

\section{Pengaruh Kompensasi terhadap Disiplin kerja guru}

Berdasarkan hasil pengujian hipotesis $\left(\mathrm{H}_{2}\right)$ telah membuktikan variabel kompensasi berpengaruh terhadap disiplin kerja guru di SMAN 1 Rao, kabupaten Pasaman. Berdasarkan tabel 4.19 diperoleh nilai $t$ hitung $>\mathrm{t}$ tabel $(2,079>2,000)$ dengan tingkat signifikan $0,042<0,05$. Dapat diartikan bahwa variabel kompensasi secara parsial berpengaruh positif dan signifikan terhadap displin kerja guru SMAN 1 Rao, kabupaten Pasaman. Oleh karena itu $\mathrm{H}_{2}$ diterima, hal ini menunjukkan bahwa semakin tinggi tingkat kompensasi maka semakin tinggi pula tingkat disiplin kerja guru, dan begitu juga sebaliknya, semakin rendah tingkat kompensasi maka semakin rendah pula disiplin kerja guru di SMAN 1 Rao.

\section{Pengaruh Budaya Organisasi Terhadap Disiplin Kerja Guru}

Berdasarkan hasil pengujian hipotesis $\left(\mathrm{H}_{3}\right)$ telah membuktikan variabel budaya organisasi tidak berpengaruh terhadap disiplin kerja guru di SMAN 1 Rao, kabupaten Pasaman. Berdasarkan tabel 4.19 diperoleh nilai $t$ hitung $<t$ tabel $(0,544<2,000)$ dengan tingkat signifikan $0,610>0,05$. Dapat diartikan bahwa variabel budaya organisasi secara parsial tidak berpengaruh terhadap disiplin kerja guru SMAN 1 Rao, kabupaten Pasaman. Oleh karena itu $\mathrm{H}_{3}$ ditolak, hal ini menunjukkan bahwa semakin rendah tingkat budaya organisasi maka semakin rendah tingkat disiplin kerja guru, dan begitu juga sebaliknya, semakin tinggi tingkat budaya organisasi maka semakin tinggi pula disiplin kerja guru di SMAN 1 Rao.

\section{Pengaruh Supervisi Kepala Sekolah, Kompensasi dan Budaya Organisasi Terhadap Disiplin Kerja Guru}

Berdasarkan hipotesis (H4) yang telah penulis lakukan bahwa secara simultan terdapat pengaruh positif dan signifikan variabel supervisi kepala sekolah, kompensasi dan budaya organisasi terhadap disiplin kerja guru seperti yang tampak pada tabel 4.20 yaitu nilai signifikan $0,00<0,05$.

Jadi dapat disimpulkan bahwa semakin tinggi tingkat supervisi, kompensasi dan budaya organisasi maka semakin tinggi pula tingkat disiplin kerja guru di SMAN 1 Rao kabupaten Pasaman.

\section{Kesimpulan}

Dari pembahasan pada bab-bab sebelumnya, maka dapat ditarik beberapa kesimpulan sebagai berikut :

1. Bahwa terdapat pengaruh positif dan signifikan variabel supervisi kepala sekolah terhadap disiplin kerja guru SMAN 1 Rao.

2. Bahwa terdapat pengaruh positif dan signifikan kompensasi terhadap disiplin kerja guru di SMAN 1 Rao.

3. Bahwa tidak terdapat pengaruh dan tidak signifikan budaya organisasi terhadap disiplin kerja guru di SMAN 1 Rao.

4. Bahwa secara bersama-sama terdapat pengaruh yang signifikan antara supervisi kepala sekolah, kompensasi dan budaya organisasi terhadap disiplin kerja guru di SMAN 1 Rao. 


\section{Daftar Pustaka}

Afandi, Pandi. 2016. Concept \& Indicator Human Resources Management for Management Research. Yogyakarta: Deepublish.

Anuril, Awal. 2019. The Effect of Supervision on Increasing the Disciplinary of Employees Work In the Large Center Of Kerinci Seblat National Park Kota Sungai Penuh. Vol. 15 No. 1 June 2019, pp. 243-247. ISSN: 2509-0119

Badaruddin dan Mardiah Safitri. Pengaruh Pengawasan Dan Kompensasi Terhadap Disiplin Kerja Pada Kantor Dinas Perindustrian Dan Perdagangan Aceh. Jurnal Manajemen dan Akuntansi Vol. 4 No 2. Th 2018 e-ISSN 2579-5635 p-ISSN 2460-5891

Hasibuan, M. S. 2016. Manajemen: Dasar, Pengertian, dan Masalah. Jakarta: PT Aksara.

Jaya, Ujang. 2015. Pengaruh Budaya Organisasi Terhadap Disiplin dan Produktivitas Wartawan Tribun Pekanbaru. Jom FEKON Vol. 2 No. 1 Februari

Mahirah. 2018. Pengaruh supervisi Kepala Sekolah terhadap disiplin kerja pegawai SMPN 1 Amali kecamatan amali kabupaten Bone Jurnal Nasional, vol 2 no tahun 2018.

Mangkunegara, A. A. A. P. 2010. Manajemen Sumber Daya Manusia. Jakarta: Raja Grafindo Persada.

Maryadi. Pengaruh Budaya Organisasi, Kompensasi, Dan Kepuasan Kerja Terhadap Disiplin Kerja Guru Sd Di Kecamatan Tengaran Kabupaten Semarang. JMP, Volume 1 Nomor 2, Agustus 2012

Rabiulkhri, Mailani. 2019. The Effect Of Compensation And Organizational Commitment To Work Discipline With Job Satisfaction As Intervening Variables In Sakinah Wedding Organizer. Econosains Volume.17 Nomor.1 Maret 2019 P (78-88). E-ISSN: 2252-8490

Robbins, S. P. 2016. Perilaku Organisasi. Jakarta: Prehalindo.

Sedarmayanti. 2017. Manajemen Sumber Daya Manusia. Bandung: PT Refika Aditama.

Setiawati, Ivonne dkk. 2019. The Effects of Organizational Culture, Leadership Style, Motivation, and Organizational Commitment on Employee Work Discipline at Pancaran Maitri Foundation. Management Research Spectrum, Vol. 9, No. 1 (2019) 42-47. ISSN: 2659-1960 (Online) ISSN: 2659-1871 (Print)

Sugiyono. 2017. Metode Penelitian Kuantitatif, Kualitatif, dan R\&D. Bandung: Alfabeta.

Sutrisno. 2016. Dasar-dasar Supervisi Kepala Sekolah. Jakarta:Rineka Cipta.

Sutrisno, Edi. 2017. Manajemen Sumber Daya Manusia Edisi Pertama. Jakarta: Kencana Prenada Media Group. 